\title{
Tuberculous Olecranon Bursitis
}

\author{
Arcot Rekha, Keerthi Kumaran, Parimuthukumar \\ Sri Ramachandra Medical College, Sri Ramachandra University, Chennai, India \\ Email: rekha a@yahoo.com
}

Received 20 March 2014; revised 18 April 2014; accepted 10 May 2014

Copyright (C) 2014 by authors and Scientific Research Publishing Inc.

This work is licensed under the Creative Commons Attribution International License (CC BY). http://creativecommons.org/licenses/by/4.0/

(c) (i) Open Access

\begin{abstract}
Olecranon bursal involvement due to tuberculosis is not often seen in literature. Involvement is often seen in the subdeltoid and trochanteric bursa, with concomitant skeletal involvement. We report a patient with isolated tuberculous granuloma of the olecranon bursa with no comorbid illness.
\end{abstract}

\section{Keywords}

\section{Olecranon Bursa, Tuberculosis}

\section{Introduction}

The etymology of the word "Bursa”, dating back to early the 19th century, originates from Latin for "purse/bag”. Anatomically, a bursa is a sac lined by synovial membrane which aids the smooth, frictionless movement across joint spaces/tendon sheaths. Around 160 bursae are present in our body, of which 11 are around the elbow.

The olecranon bursa which develops around 7 years of age is situated between the olecranon process of the ulna and the subcutaneous tissue. Inflammation of this superficial bursa is called olecranon bursitis [1] [2]. It is known by a number of popular synonyms_- “student's elbow”, “miner’s elbow”, “dartthrower’s elbow”, “dialysis elbow”, "popeye elbow”. Olecranon bursitits due to tuberculosis is seen very rarely in the absence of bony pathology.

\section{Case Report}

A 35-year-old male presented with complaints of a swelling over the left olecranon for 3 months. Patient had occasional discomfort not amounting to pain and no restriction of elbow joint movements. There was no history of trauma, fever or other constitutional symptoms. No history of any co-morbid illnesses or tuberculosis. Local examination revealed a well defined swelling of size $5 \times 4 \mathrm{~cm}$ over the left olecranon which was fluctuant (Figure 1). A previous scar was present. There was no warmth, tenderness, erythema or parabursal edema. Range of movements across the elbow joint was normal. Baseline laboratory were within normal limits and 
chest X-ray was normal. An X-ray of the left elbow showed a soft tissue swelling with no bony pathology. An ultrasonogram was done which showed a well defined anechoic area with internal echoes, suggestive of infected bursitis (Figure 2). HIV test was negative. In view of the recurrent swelling, the bursa was excised (Figure 3). The post operative period was uneventful. Histopathological examination of the bursa showed features of a tuberculous granuloma (Figure 4) and patient was started on anti tuberculous therapy.

\section{Discussion}

Olecranon bursitis can be classified as aseptic (chronic) and septic (acute). Aseptic olecranon bursitis is more common and is usually a result of repeated, low intensity trauma to the elbow as seen in miners, students, carpet-layers, book-keepers and gymnasts [3] [4]. Other rarer causes include systemic inflammatory processes like

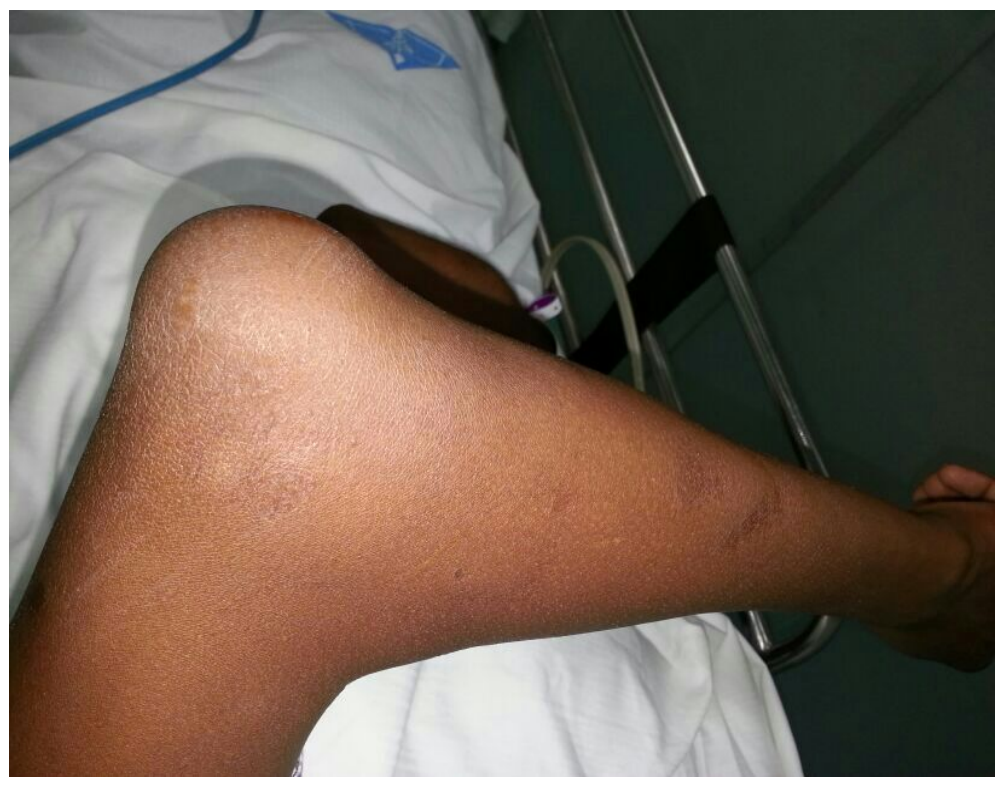

Figure 1. A photograph of the left elbow showing a well defined swelling overlying the olecranon.

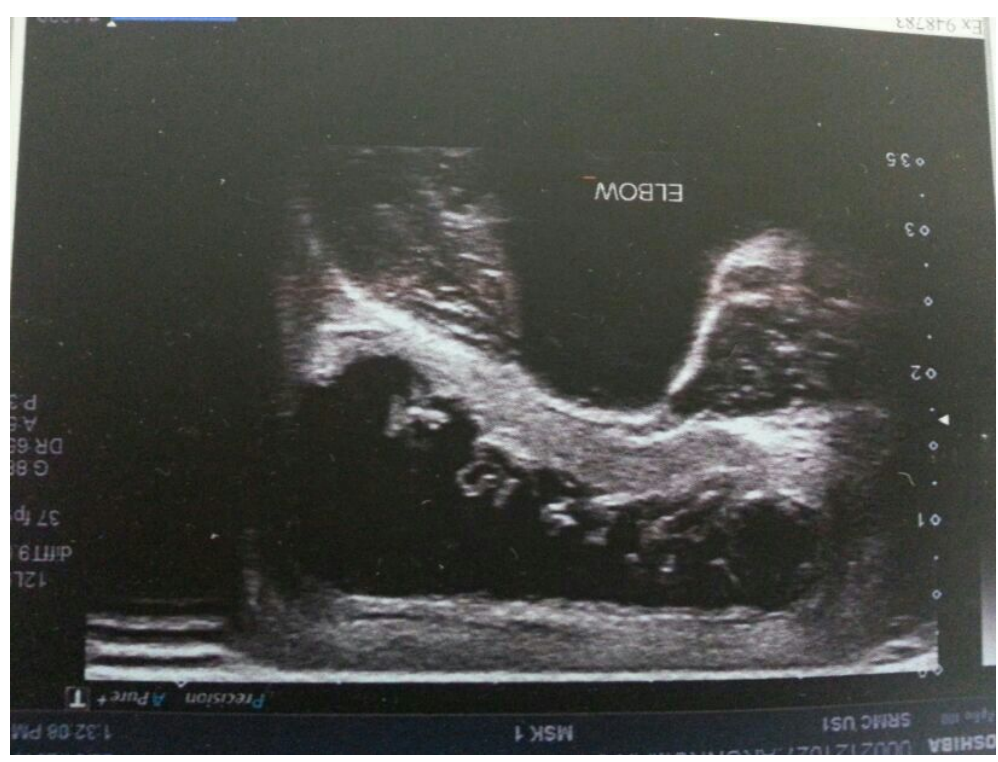

Figure 2. An ultrasonogram of the left elbow showing well defined anechoic area with internal echoes. 


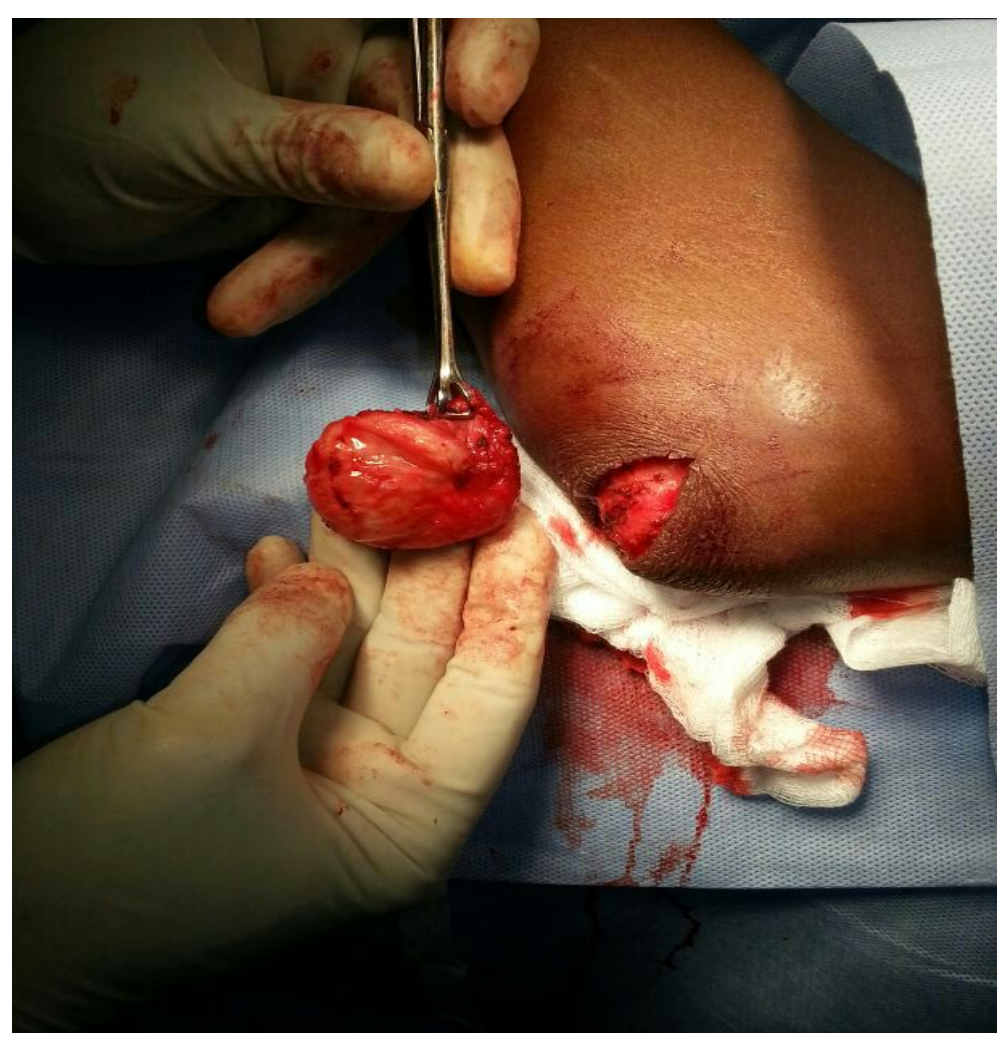

Figure 3. Complete excision of the left olecranon bursa.

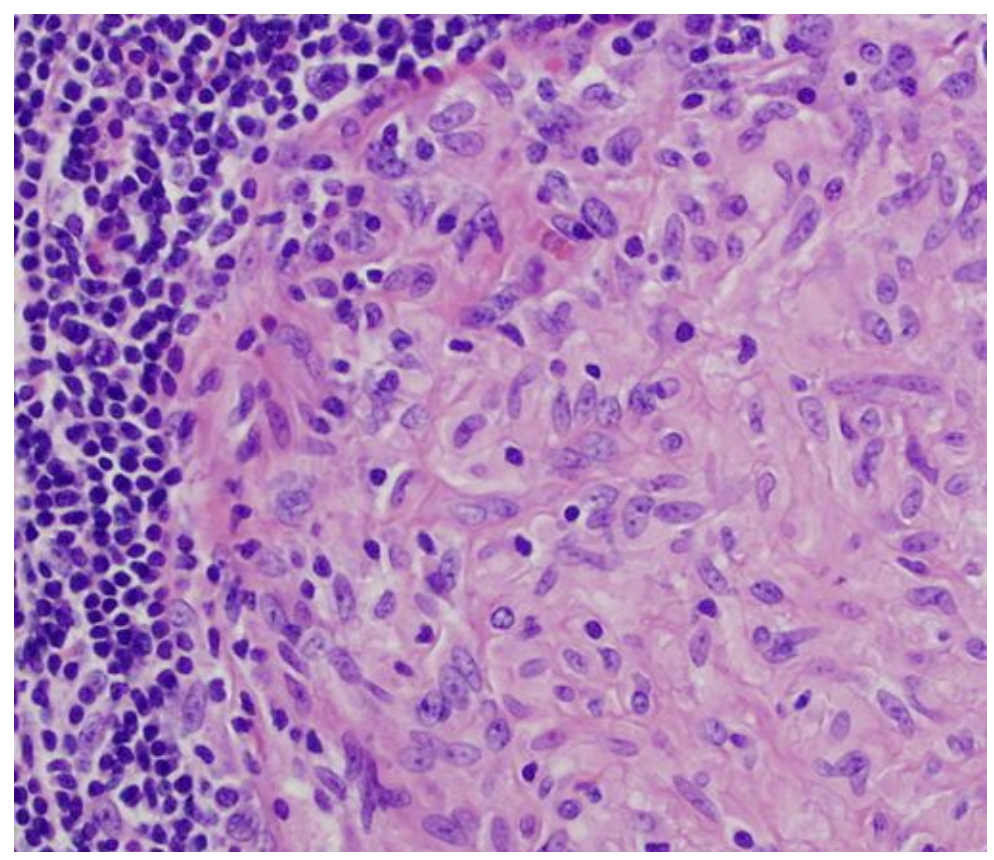

Figure 4. High power view of a tuberculous granuloma with mast cells, lymphocytes, histiocytes and giant cells.

rheumatoid arthritis, gout, systemic lupus erythematosus and pigmented villonodular synovitis. Predisposing host factors include diabetes, prolonged steroid therapy, malignancy, immunosuppressive drugs and uremia [5].

Septic olecranon bursitis accounts for about one-third of the cases and the most commonly implicated organ- 
ism is Staphylococcus aureus. Streptococcus pyogenes, Staphylococcus epidermidis, Enterococcus, Mycobacterium tuberculosis, Candida and Cryptococcus neoforman are also implicated.

Tuberculosis can affect bones, joints and the soft tissue causing arthiritis [6], osteomyelitis,tenosynovitis Isolated tuberculosis affecting bursae is very uncommon. In about $50 \%$ of the individuals a concomitant musculoskeletal or pulmonary involvement is present. Among the bursae involved, the trochanteric bursa is most commonly affected by tuberculosis. Other rare bursal involvement includes olecranon, subdeltoid and prepatellar. The portal of entry is either via direct inoculation or more commonly a hematogenous spread. Atypical mycobacteria such as Mycobacterium xenopi, Mycobacterium asiaticum, Mycobacterium goodie and Mycobacterium szulgai. have been associated with olecranon bursitis [7]-[9].

A plain X-ray of the elbow reveals a soft tissue swelling. More important indications for an X-ray are to assess for evidence of osteomyelitis, olecranon spurs, foreign bodies, concomitant fractures or pre-existing joint disease. MRI can be done to distinguish between septic and aseptic bursitis. Septic bursitis shows soft tissue enhancement, thickening of the triceps tendon and conspicuous loculations within the bursa [10]. Ultrasonogram has a high sensitivity for detecting effusions, gouty tophi, rheumatoid nodules and calcifications [11]. A sinogram may be done in the presence of a sinus tract over the swelling to ascertain any communication with the joint space. Bursal fluid aspirate can be used to distinguish septic bursitis from aseptic bursitis [12]. Bursal fluid is sent for Gram stain, culture and sensitivity, cytology, glucose levels and crystal analysis. Diagnostic indicators for septic bursitis include raised leucocyte count $(>10,000$ /cubic millimetre), polymorphonuclear predominance and bursal fluid glucose to serum glucose ratio $<50 \%$.

\section{Management}

Aseptic bursitis can be managed conservatively especially in early non-painful cases. This includes avoidance of repetitive stress to the elbow, identification and evaluation of predisposing factors and optimized use of supportive elbow pads, compression and resting splints. Judicious use of nonsteroidal anti-inflammatory drugs provides symptomatic relief to the patient. Cases that are recalcitrant to conservative management are treated by bursal aspiration under strict aseptic conditions [13]. This may or may not be followed by intrabursal injection of glucocorticoids.

Surgical management includes bursectomy i.e., complete excision of the bursa. Commonly, a longitudinal incision is made just lateral to the tip of the olecranon. The bursa is dissected from the underlying tissues and excised. Postoperatively the elbow is immobilized in a padded splint/cast in less than 60 degree flexion for about 2 weeks [14].

Septic bursitis is primarily treated by concomitant oral or parenteral antibiotics and aspiration/incision and drainage of the bursa. Bursectomy can be considered in refractory cases. Other options include injection of scleraosants like tetracycline or talcum powder.

Novel approaches like arthroscopic bursectomy [15] [16] and radiosynoviorthesis (radiation synovectomy) are being tried. Reconstructive techniques after bursectomy include fasciocutaneous flap cover taken from the forearm or the lateral arm [17]. An adipofascial flap cover may also be used.

The definitive treatment of tuberculous bursitis is complete surgical excision of the bursa although cases have been documented where complete cure has been achieved with antituberculous therapy. The antituberculous treatment should be given for at least a period of 6 months with minimum of three drugs. Postoperatively the most common complications include those associated with wound healing and recurrence [18]. Osteomyelitis of the underlying ulna is a rare but serious complication. Septic arthritis can develop if the bursa communicates with the joint space. Complications due to intrabursal steroid injection include infection, subdermal atrophy and chronic elbow pain [19].

\section{Conclusion}

Septic olecranon bursitis is seen very rarely. Tuberculous involvement of the olecranon bursa is not often seen, outside the setting of the immuno compromised. A high index of suspicion is needed to make a diagnosis and it is essential to rule out concomitant musculosketeal tuberculosis.

\section{References}

[1] Del Buono, A., Franceschi, F., Palumbo, A., Denaro, V. and Maffulli, N. (2012) Diagnosis and Management of Olecra- 
non Bursitis. Surgeon, 10, 297-300. http://dx.doi.org/10.1016/j.surge.2012.02.002

[2] Baumbach, S.F., Lobo, C.M., Badyine, I., Mutschler, W. and Kanz, K.G. (2013) Prepatellar and Olecranon Bursitis: Literature Review and Development of a Treatment Algorithm. Archives of Orthopaedic and Trauma Surgery, 134, 359-370. http://dx.doi.org/10.1007/s00402-013-1882-7

[3] Wasserzug, O., Balicer, R.D., Boxman, J., Klement, E., Ambar, R. and Zimhony, O. (2011) A Cluster of Septic Olecranon Bursitis in Association with Infantry Training. Military Medicine, 176, 122-124. http://dx.doi.org/10.7205/MILMED-D-10-00117

[4] Senécal, L. and Leblanc, M. (2001) Olecranon Bursitis in Chronic Haemodialysis Patients. Nephrology Dialysis Transplantation, 16, 1956-1957. http://dx.doi.org/10.1093/ndt/16.9.1956

[5] Gregory, T., Mir, O., Medioni, J., Augereau, B. and Oudard, S. (2010) Olecranon Bursitis in Patients Treated with Sunitinib for Renal Cell Carcinoma. Medical Oncology, 27, 446-448. http://dx.doi.org/10.1007/s12032-009-9231-y

[6] Holder, S.F., Hopson, C.N. and Vonkuster, L.C. (1985) Tuberculous Arthritis of the Elbow Presenting as Chronic Bursitis of the Olecranon. A Case Report. The Journal of Bone \& Joint Surgery, 67, 1127-1129.

[7] Malkin, J., Shrimpton, A., Wiselka, M., Barer, M.R., Duddridge, M. and Perera, N. (2009) Olecranon Bursitis Secondary to Mycobacterium Kansasii Infection in a Patient Receiving Infliximab for Behcet's Disease. Journal of Medical Microbiology, 58, 371-373. http://dx.doi.org/10.1099/jmm.0.006809-0

[8] Friedman, N.D. and Sexton, D.J. (2001) Bursitis Due to Mycobacterium Goodii, a Recently Described, Rapidly Growing Mycobacterium. Journal of Clinical Microbiology, 39, 404-405. http://dx.doi.org/10.1128/JCM.39.1.404-405.2001

[9] Wastiaux, H., Maillard, H., Bara, C., Catala, S., Steff, M. and Célérier, P. (2008) Bursitis Due to Mycobacterium Intracellulare in an Immunocompetent Patient. Annales de Dermatologie et de Venereologie, 135, 492-495. http://dx.doi.org/10.1016/j.annder.2007.11.034

[10] Floemer, F., Morrison, W.B., Bongartz, G. and Ledermann, H.P. (2004) MRI Characteristics of Olecranon Bursitis. AJR American Journal of Roentgenology, 183, 29-34. http://dx.doi.org/10.2214/ajr.183.1.1830029

[11] Blankstein, A., Ganel, A., Givon, U., Mirovski, Y. and Chechick, A. (2006) Ultrasonographic Findings in Patients with Olecranon Bursitis. Ultraschall in der Medizin, 27, 568-571. http://dx.doi.org/10.1055/s-2006-926569

[12] Schumacher, H.R. (1993) Arthrocentesis, Synovial Fluid Analysis, and Synovial Biopsy. In: Schumacher, H.R., Ed., Primer on Rheumatic Diseases, 10th Edition, Arthritis Foundation, Atlanta, 67-72.

[13] Olsen, N.K., Press, J.M. and Young, J.L. (1995) Bursal Injections. In: Lennard, T.A., Ed., Physiatric Procedures in Clinical Practice, Hanley \& Belfus, Philadelphia, 36-43.

[14] Walter, G., Kemmerer, M. and Hoffmann, R. (2013) Treatment of Septic Olecranon and Patellar Bursitis by Excision and Vacuum-Assisted Closure Therapy. Zeitschrift für Orthopädie und Unfallchirurgie, 151, 353-357. http://dx.doi.org/10.1055/s-0033-1350612

[15] Ogilvie-Harris, D.J. and Gilbart, M. (2000) Endoscopic Bursal Resection: The Olecranon Bursa and Prepatellar Bursa. Arthroscopy, 16, 249-253. http://dx.doi.org/10.1016/S0749-8063(00)90048-3

[16] Tu, C.G., McGuire, D.T., Morse, L.P. and Bain, G.I. (2013) Olecranon Extrabursal Endoscopic Bursectomy. Techniques in Hand and Upper Extremity Surgery, 17, 173-175. http://dx.doi.org/10.1097/BTH.0b013e31829c0535

[17] Mac Quillan, A., Josty, I.C. and Murison, M.S. (2002) Deepithelialized Double-Breasted Flap with Synovectomy of the Elbow: New Technique for the Management of Refractory Olecranon Bursitis. Annals of Plastic Surgery, 48, 451452. http://dx.doi.org/10.1097/00000637-200204000-00028

[18] Degreef, I. and De Smet, L. (2006) Complications Following Resection of the Olecranon Bursa. Acta Orthopaeligdica Belgica, 72, 400-403.

[19] Weinstein, P.S., Canoso, J.J. and Wohlgethan, J.R. (1984) Long-Term Follow-Up of Corticosteroid Injection for Traumatic Olecranon Bursitis. Annals of the Rheumatic Diseases, 43, 44-46. http://dx.doi.org/10.1136/ard.43.1.44 